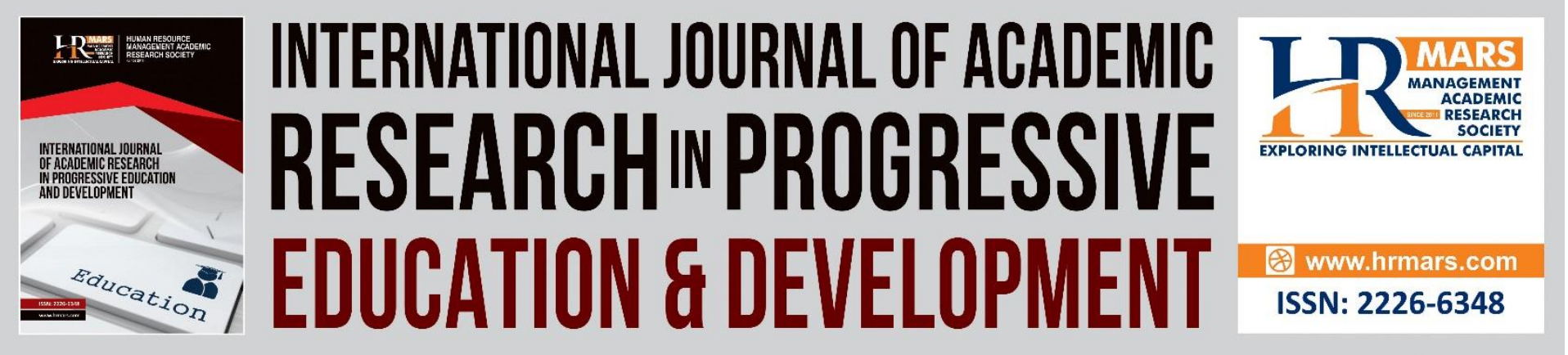

\title{
Exploring the Implementation of Teaching and Learning Using Virtual Learning Among Elementary School Science Teachers in Malaysia
}

Mat, H., Mustakim, S. S., Arshad, M. M., Razali, F.

To Link this Article: http://dx.doi.org/10.6007/IJARPED/v11-i1/12118

DOI:10.6007/IJARPED/v11-i1/12118

Received: 13 November 2021, Revised: 19 December 2021, Accepted: 06 January 2022

Published Online: 26 January 2022

In-Text Citation: (Mat et al., 2022)

To Cite this Article: Mat, H., Mustakim, S. S., Arshad, M. M., \& Razali, F. (2022). Exploring the Implementation of Teaching and Learning Using Virtual Learning Among Elementary School Science Teachers in Malaysia. International Journal of Academic Research in Progressive Education and Development, 11(1), 595-605.

Copyright: (C) 2022 The Author(s)

Published by Human Resource Management Academic Research Society (www.hrmars.com)

This article is published under the Creative Commons Attribution (CC BY 4.0) license. Anyone may reproduce, distribute, translate and create derivative works of this article (for both commercial and non-commercial purposes), subject to full attribution to the original publication and authors. The full terms of this license may be seen

at: http://creativecommons.org/licences/by/4.0/legalcode

Vol. 11(1) 2022, Pg. 595 - 605

Full Terms \& Conditions of access and use can be found at http://hrmars.com/index.php/pages/detail/publication-ethics 


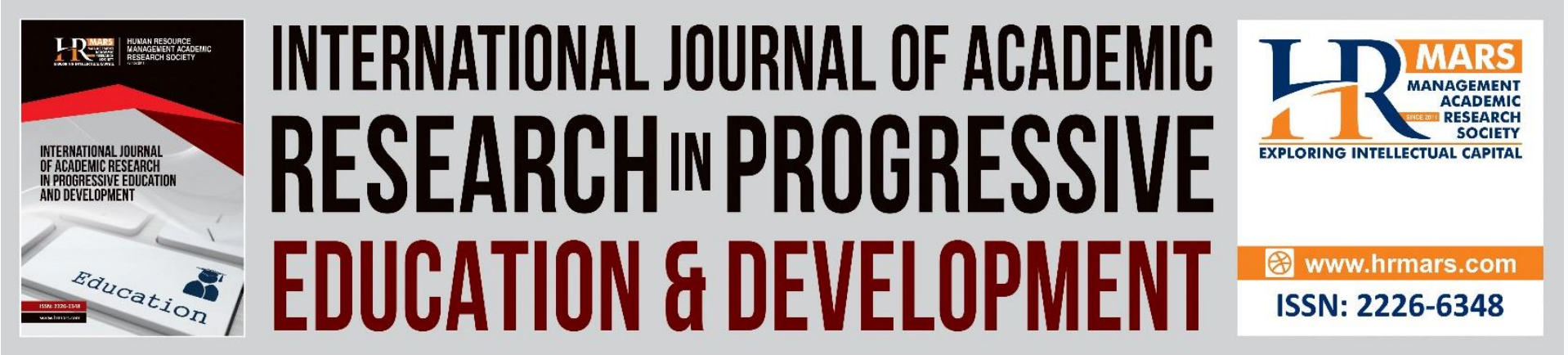

\title{
Exploring the Implementation of Teaching and Learning Using Virtual Learning Among Elementary School Science Teachers in Malaysia
}

\author{
Mat, H., Mustakim, S. S., Arshad, M. M., Razali, F. \\ Faculty of Educational Studies, Universiti Putra Malaysia, 43400 Seri Kembangan, \\ Selangor, Malaysia \\ Correspondence Author Email: mssalina@upm.edu.my
}

\begin{abstract}
This paper discusses the implementation of Interactive Virtual Learning (VL) among elementary school teachers in Malaysia. The qualitative method of unstructured interviews and observation was chosen as the way for gathering information to discover the existing challenge that teachers confront in excelling in science, as well as the necessity for any new instructional tactics. Two primary school science teachers from two different schools were selected to participate in this interview. The results of this preliminary investigation confirm that modern science teachers confront challenges in their classrooms. The findings suggest a scarcity of high-quality learning materials on which they may rely. Furthermore, a lack of time for revision and exploration of each topic is a problem that must be addressed to improve student performance in science. Finally, the integration of VL with various learning strategies must be designed and developed to facilitate and boost students' learning abilities in the topic of science.
\end{abstract}

Keywords: Virtual Learning, Learning Science, Computer-Assisted Learning, E-Learning, Mastery Learning, Cooperative Learning

\section{Introduction}

The rapid growth of $\mathrm{VL}$, along with the ever-increasing number of internet users globally, has resulted in more chances for knowledge and information access (Wallet \& Valdez, 2014; UNESCO Bangkok, 2015). Many countries have responded to the growing importance of VL by attempting to transform school education from traditional face-to-face, teacher-centered teaching and learning to a student-centered environment that extends beyond the classroom, as well as exposing students to pedagogical approaches that encourage interactivity and the development of 21st-century skills (Teoh, 2015; Robertson, 2016).

A previous study (Aziz et al., 2019; Phong et al., 2020) has demonstrated that teachers' usage of technology in the classroom is linked to their perceptions about its worth. Teachers can use whichever teaching methods they like. Some teachers utilize YouTube to communicate 
with their pupils and deliver information for review, while others use whatever technique they can.

The Ministry of Education (MOE) has introduced several different online teaching methods. If online education was merely used as a teaching tool in the past, it was not the major mode of instruction. However, in the case of a crisis and the imposition of the Movement Control Order (MCO), online teaching is already regarded as the primary mode of instruction. As a result, now is the moment for teachers to reinforce this online teaching and learning, particularly for future usage.

\section{Issues and Challenges}

Previous study has placed a great deal of emphasis on the importance of science for employment, especially for global significance (Li et al., 2020), improving the career aspiration (Rice et al., 2013; Badri et. al, 2016), and help develop the students' motivation and potential (Dare, Ellis \& Roehrig, 2018). Accordingly, the strengthening of thinking abilities at elementary school level is necessary in the context of the present development.

However, many elementary schools students unable to master Higher Order Thinking Skills (Mat \& Yusoff, 2019) because of some factor like non proper learning model (Novita, 2014), and the fact-memorizing phenomenon (Azian et al, 2017). As a consequence, the HOTS level among elementary school students still at a low level.

Due to the fact that teachers exclusively utilise whiteboards and pen markers while imparting information, the chalk and talk strategy functions as a traditional educational approach only allows for one-way communication (Shah et al., 2017), which students are only encouraged to voice their opinions or answer questions when the teachers asks them. It is often necessary for pupils to duplicate what is written on the whiteboard in order to pass a class. The traditional technique, known as chalk and talk, is no longer necessary for order to meet the demands of today's leaners (Jabeen \& Ghani, 2015). So that, the purpose of the study was to explore the implementation of teaching and learning using virtual learning among elementary school science teachers in Malaysia.

\section{Methods}

This exploratory, the qualitative study included two science teachers from two elementary schools. Table 1.1 shows the profiles of the teachers. Due to cautious measures implemented during the research time, the author questioned all teachers via Google Meet. Each teacher interview lasted about 60 minutes.

Table 1.1 : The details of science teachers interviewed

\begin{tabular}{lll}
\hline No & School & Level teaching \\
\hline 1 & School A & Year 4,5 and 6 \\
\hline 2 & School B & Year 4,5 and 6 \\
\hline
\end{tabular}

Teachers described their experiences creating VL, science lessons, how they planned lessons to engage teachers, and their opinions of student participation in a semi-structured interview. The questions in the Appendix directed the semi-structured interview, with additional 
questions added as the interview continued based on the teachers' responses. For the sake of analysis, all interviews were transcribed. Thematic analyses from the ground up were carried out in stages. Throughout the analysis, members were checked to ensure that the findings were valid and reliable.

Phase one consists of basic data coding and familiarisation. The researchers read the transcripts of the interviews. Annotations were added to the basic codes to emphasize important factors that teachers effectively address when creating $V L$ experiences and their observations of student involvement.

The second phase is analysing codes and identifying themes. To understand alternative interpretations and align any inconsistencies, the researchers discussed their initial codes. Combining the basic codes resulted in the first set of themes.

Reviewing and defining topics is the third phase. Smaller topics were combined to produce larger themes, or broader themes were divided into subthemes, and initial concepts were reevaluated. The researchers repeated this process until they came up with a thematic map that effectively described their findings.

\section{Findings}

In the final thematic map, the findings are organised into two main themes and four subthemes (see Fig. 1.1). The first theme delves into teacher VL considerations in terms of (a) design preparations and implementations, and (b) community-based professional development. In Theme 2, teachers' descriptions of students' VL involvement and preparation are used to highlight students' VL determinants.

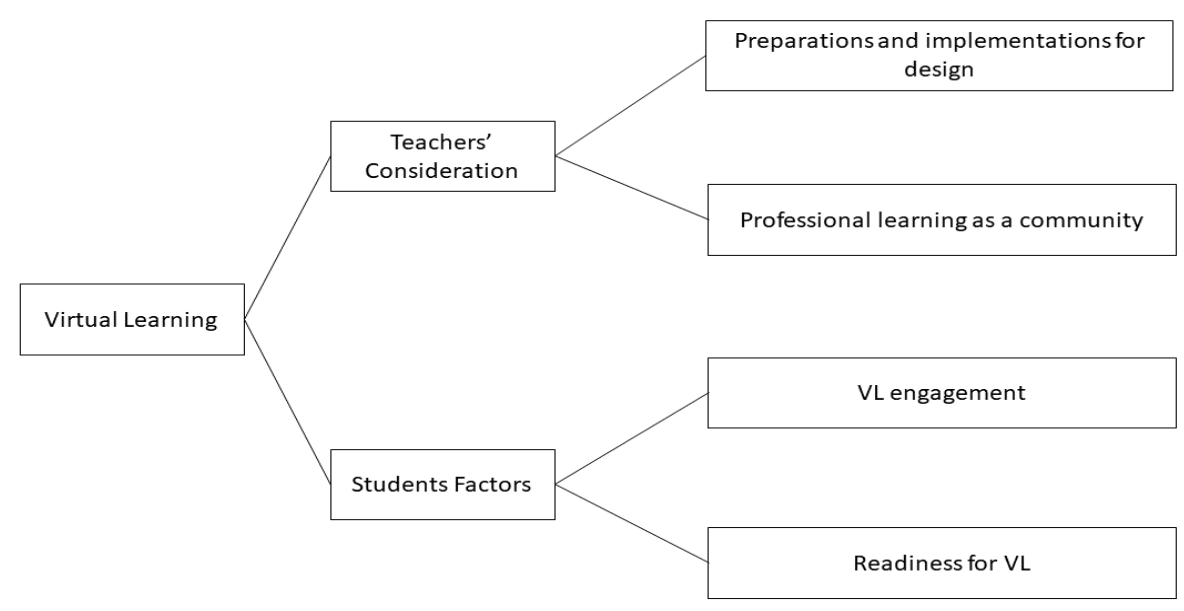

Fig. 1.1: Thematic map

\section{Theme One: Teachers' Considerations for VL}

The first theme looks at how teachers prepare and implement virtual lessons using a combination of the use of learning modules along with instructional videos. Teachers work collaboratively to provide the technology used and plan lessons to ensure students do not drop out of teaching and learning activities. Teachers collaborate with fellow teachers from 
other states by collecting and sharing virtual learning resources that allow teaching and learning to continue.

"I am one of the volunteers of the Malaysian Youtuber Academy. Through this academy we are taught how to produce quality teaching videos and according to the latest syllabus issued by the Ministry of Education Malaysia. We also discuss what we want to do with our students, then share and cross-pollinate ideas."

[IV: T1: 17.09.21]

On the other hand, the school schedule was restructured to better monitor students' screen time. Teachers used WhatsApp, Telegram, Facebook, and/or YouTube to integrate VL, and they supplemented it with additional technologies (e.g., Google apps). Technology familiarisation classes were given to teachers who wanted instruction on how to use internet tools for VL. Teachers also used the Ministry of Education's Facebook page to share lesson ideas and materials with teachers from other schools (Malaysia).

Besides that, VL was used in both synchronous and asynchronous forms to emphasise subject content delivery and monitor students' learning.

"It's a mix of synchronous and asynchronous instruction. It's based on the lesson's difficulty level and the type of student profile."

[IV: T2: 18.09.21]

Teachers may use a greater number of virtual learning techniques with level 2 students than they can with level 1 students. Typically, lessons are divided into three sections: (1) teaching the subject matter of the lesson; (2) assigning tasks and checking for student faults; and (3) explaining the comprehension of the idea of learning via question and answer sessions. Teachers are aware that they need additional time to develop instructional materials for their students. Consequently, they make extensive use of pre-existing resources like as the Akademi Youtuber Malaysia online or teacher groups on social media sites like Facebook. Additionally, teachers assist one another by sharing their teaching materials with members of the community, both within and outside of the school.

To match classroom practice, alignment and learning activities are implemented using video conferencing software such as Zoom, Google Meet or directly from the YouTube channel.

\begin{abstract}
"There was a lot of emphasis on using Google Meet and Zoom for video conferencing... a lot of what was being provided was the same thing, frontal teaching, classroom instruction. Perhaps the lesson cannot be one hour long for the $V L$ to be successful... for one hour is pretty taxing on the eyes... It takes about 35-40 minutes."
\end{abstract}

[IV: T1: 17.09.21]

"Not all teachers will be able to offer lessons entirely online. This is since the internet connection is less stable. As a result, I will adjust my plans in accordance with the adequacy of the internet line scenario. Sometimes I just post a YouTube 
video link, and other times it simply provides activities to students, who may do the tasks at their convenience..."

[IV: T2: 18.09.21]

Synchronous lessons lasted 35 to 40 minutes. Because teachers were conscious of pupils' attention spans, each part lasted no more than 15 minutes. Pupils, particularly absentees, were able to review courses once they were digitally filmed and published to YouTube or Google Classroom. Teachers found it difficult to keep track of their pupils' online involvement and learning because they could be multitasking. Furthermore, pupils could plagiarise responses from web sources because of the 'cut and paste' technological capability. The first and third portions pertain to classes that have not been deployed in live sessions to this point. When students need to access lessons, resources provided by the teachers, they may only utilise telegrams or WhatsApss. Teachers will provide instructional video links through YouTube or self-training connections via Google Forms, Quizzes, Kahoots, and other similar tools with students. Teachers utilise the self-marking option to keep track of their students' progress and comprehension. Teachers also urged pupils to store their homework assignments online so that they may study them later.

Teachers also participated in online courses to learn about new software programmes to help $\mathrm{VL}$ and to stay up to date with the most recent technological tools and developments.

"There were several online learning platforms available. So, the headmaster will tell us, oh, if you want to learn how to utilize Google Classroom, there is this online course, tutorial, or anything along those lines..."

[IV: T1: 17.09.21]

Teachers and technical employees used emails and mobile phone applications (e.g. WhatsApp, Telegram) to conduct occasional troubleshooting to ensure the VL ran well. Talking about this issue an interviewee said:

"We received professional development... Then, throughout the VL era, we were quite active on WhatsApp level chat, saying things like, "Oh, I'm having trouble with this and all, what should I do?" As a result, we're assisting one another... Yeah, that's a big benefit."

[IV: T2: 18.09.21]

The teaching community helped each other by sharing different ideas and opinions for using technology in teaching and learning.

As one interviewee said, VL demanded more time and resources. It was not necessary for them to have or learn about cutting-edge technology in order to do VL.

"It isn't so much about the number of apps to learn how to use currently. It's more of a question of, ok, how can you increase your zoom usage? ......, l'd like to learn how to use those apps more effectively. Learn more about the varied components of these programmes, including zoom, where you can divide them into different chat groups and have them discuss certain subjects before returning to the main class."

[IV: T1: 17.09.21] 
DEVELOPMENT

Vol. 11, No. 1, 2022, E-ISSN: 2226-6348 @ 2022 HRMARS

More professional learning opportunities for teachers were needed that focused on understanding and implementing technological affordances to create meaningful learning experiences. Both within and between schools, teachers were excited about sharing resources and teaching ideas.

\section{Theme Two: Student' Factors for VL}

The next topic discusses the amount of concern, taking into consideration pupils' engagement and preparedness for VL. Both sub-themes reflect teachers' concerns for fostering students' emotional, behavioural, cognitive, and social involvement during $V L$, as well as teachers' comprehension of how technology accessibility, maturity, and age affect students' preparation for VL.

This result suggests that teachers need to take into consideration students' emotional engagement when designing and enacting VL experiences. Students were excited to begin their online VL experience because of the curiosity effects of technology. Students were quite enthusiastic about the Google Meet software program even before the VL period when they were taken to the computer lab to familiarise themselves with it. Fatigue came in as the weeks passed.

"It was like a brand-new platform to them; it was like a novelty. So, you see, I guess it wears off after a while."

[IV: T1: 17.09.21]

"Most of the students who were active in the class expressed concern with their level of academic achievement as they did not have mid -year exams or assessments in any other form. However, for students who are silent in the classroom has shown a difference when they start asking questions during the virtual learning activities are implemented. This is because in a physical classroom, students who are outspoken will have an advantage over students who are relatively quiet.."

[IV: T2: 18.09.21]

Web conferencing is used by teachers in the lesson to monitor student progress, discuss about personal issues and maintain a level of emotional equilibrium. Additionally, teachers collaborate with parents and guardians to make certain that students get the emotional support they need while participating in virtual learning activities.

Learning was aided by the VL environment since students were able to concentrate without being disturbed by their colleagues. In comparison to the classroom, "quietness" could be maintained in the online setting since teachers could mute all or some pupils. The technology could be used to control chatty or unruly kids. One surprising finding was that pupils who were normally silent and unresponsive in face-to-face situations were proactive in asking questions and actively participated.

Students being late, absent, multitasking, and submitting late homework are all challenges that have occurred as a result of the internet environment. Teachers must call pupils or their parents/guardians to find out why they were late or absent in some cases. Teachers kept track of pupils' behaviour by asking them to turn on their webcams to record attendance and verify their identities. Teachers wanted to make sure that kids were always 
at their laptops and paying attention. Teachers also noted that in an online setting, students needed more "chasing" to submit their homework.

Teachers recognized the importance of online formative evaluations in online VL for gathering feedback from students on their knowledge and development. Unlike in a physical classroom, where such comments could be given quickly and easily, the online setting necessitated planning. As a result, teachers had to change their methods.

"One of the issues I saw with home-based learning was that there was less face time, making it more difficult for us to provide feedback." Instantaneous feedback So, much like when we conduct face-to-face sessions, I can walk around and point out their problems right away." [IV: T1: 17.09.21]

Teachers also noted that younger or part of the online required greater coaching because online VL presented new learning problems as well as technological demands. These pupils required home support to facilitate cognitive engagement, even when lesson packages were well-designed.

Peer-to-peer talks were less common in online VL environments, according to teachers. Teachers, on the other hand, had suspicions that pupils were having discussions outside of class.

"They will, for example, chat with each other outside of class, either by calling or messaging each other. We discovered this when conversing with them in the morning."

[IV: T2: 18.09.21]

During online asynchronous lessons, most interactions occurred between the teacher and the pupils. Teachers believed that the lack of student-to-student contact was since teachers kept lessons to 30-40 minutes. The capacity to use technology has an impact on students' VL preparation. To access online VL, some pupils lacked technological gadgets or had to share technological devices with siblings.

Teachers believe that students' maturity, as measured by self-direction, motivation, and ICT knowledge, as well as their age, played a factor in their participation in the online VL experience.

"With the younger ones, I see a general trend. I believe they aren't used to it. This entire virtual learning experience. The older ones, I believe, adjust much more quickly. Then, for your specialized groups' really, extremely low progress, video conferencing greatly benefited them. For VL to be effective, kids with lower progress and specific needs needed face-to-face experiences with instructor scaffolding and supervision at home. We need to keep an eye on things. So, in most cases, we watch these pupils and discover that they have a problem, in that they are unable to study at home. This is known as a special need, and they must call back to school."

[IV: T1: 17.09.21] 
DEVELOPMENT

Vol. 11, No. 1, 2022, E-ISSN: 2226-6348 @ 2022 HRMARS

Younger kids, particularly those in level 1 (Years 1-3), required more synchronous learning experiences and parental support. Level 2 pupils (year 4-6) appeared to be more self-directed and capable of coping with asynchronous lessons. Students with special needs were given special permission to return to school so that teachers may conduct one-on-one or small group classes for them.

\section{Discussion and Implications}

The research yielded five recommendations for online VL experiences based on the two categories (see Table 2). These suggestions are detailed further down.

Table 2 Summary of practical implications

\begin{tabular}{ll}
\hline Theme one: teacher considerations & Theme two: student factors \\
\hline $\begin{array}{l}\text { Teachers must measure students' } \\
\text { involvement and progress purposefully } \\
\text { and consistently. }\end{array}$ & $\begin{array}{l}\text { Expand online learning spaces to include } \\
\text { social media platforms so that pupils can } \\
\text { continue discussions outside of class. }\end{array}$ \\
$\begin{array}{ll}\text { Teachers deliver lessons using several } \\
\text { advanced platforms. }\end{array}$ & $\begin{array}{l}\text { Instil skills and habits of learning into } \\
\text { students in both online and face-to-face } \\
\text { settings. }\end{array}$ \\
$\begin{array}{l}\text { Teachers require ongoing professional } \\
\text { development to learn how to use } \\
\text { instructional strategies and technological } \\
\text { affordances more effectively for } \\
\text { meaningful learning with technology. }\end{array}$
\end{tabular}

Virtual learning makes monitoring student progress more challenging than face -to face learning. Changes in the education system that were previously implemented face -to face to virtual learning, have changed the teaching and learning situation. As noted by (Chai et al., 2010; Chai et al., 2019) in the TPACK framework, teachers now need to examine the interaction of technology, pedagogy, and content in building virtual learning experiences. Other elements considered include talent, emotions, ways of student engagement, their performance in assessment and interaction (Dixson, 2015; Martin \& Bolliger, 2018). Therefore, there is a need for a guide to facilitate the process of virtual teaching and learning.

Maintaining student involvement is important for effective learning. Teachers interviewed expressed concerns about their pupils' participation in the VL experience. In a face-to-face format, our teachers felt they could better observe pupils' cognitive, behavioural, emotional, and social engagement. This study have proven to reveal some connections between the three dimensions of student engagement. While teachers are concerned about their students' understanding of content, the practical implication of these VL experiences is that learners' behavioural and emotional engagement was crucial in supporting cognitive engagement. Teachers must actively develop communication opportunities for students throughout online $\mathrm{VL}$ encounters to learn about their problems and wants and maintain a two-way communication channel. 
In conclusion, virtual learning can indeed help transform teaching and learning activities to be more comprehensive, meaningful and student -centred, with better access to educational resources. As illustrated through the findings of the study, teachers who have a sense of ownership or empowerment will contribute to higher technology integration in teaching and learning activities. Nevertheless, it is important to identify the factors that motivate teachers to use virtual learning. Data from teacher perspective mapping, as well as other data collected in this study will be useful as a reference for MOE and teachers in improving the use of virtual learning, and generally improving the integration of technology in education.

\section{References}

Adnan, A. H. M. (2020). From interactive teaching to immersive learning: Higher Education 4.0 via 360-degree videos and virtual reality in Malaysia. International Conference on Technology, Engineering and Sciences (ICTES) 2020. doi:10.1088/1757899X/917/1/012023

Azian A. A., Fauziah, I., Mala, N. I., Norhanim, A. S. (2017). Investigating the Implementation of Higher Order Thinking Skills in Malaysian Classrooms: Insights from L2 Teaching Practices. Sains Humanika 9: 4-2 (2017) 65-73. www.sainshumanika.utm.my | e-ISSN ISSN: 2289-6996

Aziz, M. A. A., Talib, O., Sulaiman, T., \& Kamarudin, N. (2019). The Implementation of Flipped Classroom Instructional to Enhance Academic Achievement among Form Four Chemistry Students. International Journal of Academic Research in Business and Social Sciences, 9(7), 967-980.

Badri, M., Alnuaimi, A., Mohaidat, J., Al Rashedi, A., Yang, G., \& Al Mazroui, K. (2016). My science class and expected career choices-a structural equation model of determinants involving Abu Dhabi high school students. International Journal of STEM Education, 3(1), 12. http://doi.org/10.1186/s40594-016-0045-0

Chai, C. S., Koh, J. H. L., \& Tsai, C.-C. (2010). Facilitating preservice teachers' development of technological, pedagogical, and content knowledge (TPACK). Journal of Educational Technology \& Society, 13(4), 63-73.

Chai, C. S., Hwee Ling Koh, J., \& Teo, Y. H. (2019). Enhancing and modelling teachers' design beliefs and efficacy of technological pedagogical content knowledge for 21st century quality learning. Journal of Educational Computing Research, 57(2), 360-384

Dare, E. A., Ellis, J. A., \& Roehrig, G. H. (2018). Understanding science teachers' implementations of integrated STEM curricular units through a phenomenological multiple case study. International Journal of STEM Education, 5, 4. https://doi.org/10.1186/s40594-018-0101-z

Dixson, M. D. (2015). Measuring student engagement in the online course: The Online Student Engagement scale (OSE). Online Learning, 19(4), n4.

Jabeen, N., Ghani, A. (2015). Comparison of The Traditional Chalk and Board Lecture System Versus Power Point Presentation as a Teaching Technique for Teaching Gross Anatomy to The First Professional Medical Students, Journal of Evolution of Medical and Dental Sciences, Vol. 4, No. 11, 1811-1817.

Li, Y., Wang, K., Xiao, Y., \& Froyd, J. E. (2020). Research and trends in STEM education: a systematic review of journal publications. International Journal of STEM Education, 7, 11. https://doi.org/10.1186/s40594-_020-00207-6 
Mat, H., \& Yusoff, N. A. N. (2019). The Effect of Edutainment on Higher Order Thinking Skills among Year Five Students. International Journal of Academic Research in Progressive Education and Development, 8(4), 55-65.

Martin, F., \& Bolliger, D. U. (2018). Engagement matters: Student perceptions on the importance of engagement strategies in the online learning environment. Online Learning, 22(1), 205-222.

Melor M. Y., Nurulhusna Y., \& Ashairi S. (2020). Universal Journal of Educational Research 8(3): 879-887, 2020. DOI: 10.13189/ujer.2020.080319

Novita, G. D. (2014). The Influence PBL against Science Process Skills Student Class V SD in Cluster IV Diponegoro Mendoya district. Pulpit Journal PGSD Ganesha Education University.

Phoong S. Y., Phoong S. W., Phoong K. H. (2020). The Effectiveness of Frog Virtual Learning Environment in Teaching and Learning Mathematics. Universal Journal of Educational Research 8(3B): 16-23, 2020. DOI: 10.13189/ujer.2020.081502

Rice, L., Barth, J. M., Guadagno, R. E., Smith, G. P. A., \& McCallum, D. M. (2013). The Role of Social Support in Students' Perceived Abilities and Attitudes Toward Math and Science. Journal of Youth and Adolescence, 42(7), 1028-1040. http://doi.org/10.1007/s10964012-9801-8

Robertson, J. (2016). Moray House School of Education Election Briefings Digital Education Building a critical understanding of technology in everyday life. [Online] Available at:http://www.ed.ac.uk/files/atoms/files/electionbriefing2-digital-education-29-0316.pdf?utm_source=Briefing\&utm_medium=DigitalEd2\&utm_content=election\&utm_ campaign= MorayHouseBriefing

Shah, T., Patel, M. A., Shah, H. (2017). A Comparative Study on the Teaching Effectiveness of Chalk \& Talk Versus Microsoft PowerPoint Presentation-An Institution Based Pilot Study of Physiotherapy Students, International Journal of Current Research and Review, Vol. 9, No. 11, 40-43.

Teoh, B. H. (2015). 1BestariNet: A Malaysian Experience. In Central Asia Symposium on ICT in Education 2015 Fostering an Enabling Environment for Teacher Innovation : From Policy to Practice, pp. 1-41.

UNESCO Bangkok. (2015). Central Asia Symposium on ICT in Education 2015 Fostering an Enabling Environment for Teacher Innovation : From Policy to Practice. In Central Asia Symposium on ICT in Education 2015

Valenti, S. S., Masnick, A. M., Cox, B. D., \& Osman, C. J. (2016). Adolescents and Emerging Adults Implicit Attitudes about STEM Careers: "Science is Not Creative." Science Education International, 27(1), 40-58.

Vicneas M., \& Zamzuri, A. M. A. (2019). Different Realism Designs of 2D Virtual Agents and its' Arousal Effect on Students' Emotions in Learning. International Journal of Engineering and Advanced Technology (IJEAT) ISSN: 2249 - 8958, Volume-9 Issue-1, October 2019.

Wallet, P., \& Valdez, B. (2014). ICT in Education in Asia: A comparative analysis of ICT integration and e - readiness in schools across Asia. Montreal, Quebec, Canada: UNESCO-UIS. 